
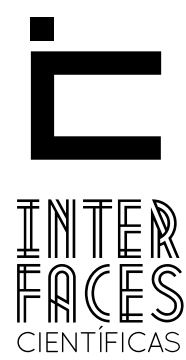

DIREITO

\title{
O RECONHECIMENTO DO DIREITO AO ESQUECIMENTO E O MACHISMO JUDICIAL
}

\author{
Hêica Souza Amorim ${ }^{1}$
}

\section{RESUMO}

O objeto desta pesquisa reflete sobre a aplicação do direito ao esquecimento e machismo judicial. 0 objetivo é investigar o reconhecimento do direito ao esquecimento como ferramenta de tutela à dignidade da pessoa humana e a tendenciosa desigualdade de gênero perpetrada por parte do STJ por ocasião do julgamento dos casos em comento. Para tanto, utilizou-se o método dedutivo, com subsídio em pesquisa bibliográfica e documental e a sucessão de três etapas. Na primeira, buscou-se examinar o discurso judicial com a observância de alguns casos julgados pelo STJ, estabelecendo-se alguns fundamentos que sustentam o direito ao esquecimento. Na segunda, estudou-se o princípio da dignidade da pessoa humana e os fundamentos para o reconhecimento do direito ao esquecimento sob o enfoque do marco normativo brasileiro e trans- nacional e doutrinário. Na terceira e última etapa, investigou-se que o STJ foi tendencioso à desigualdade de gênero no que incumbe ao reconhecimento do direito ao esquecimento de alguns casos julgados. A principal conclusão que se chegou é que é adequada a fundamentação jurídica do direito ao esquecimento, pois tal direito decorre da dignidade da pessoa humana e é categorizado como bem da personalidade, por outro lado, se aponta o machismo judicial do STJ de forma a reconhecer o direito ao esquecimento aos autores do sexo masculino e rejeitá-lo a autores do sexo feminino.

\section{PALAVRAS-CHAVE}

Dignidade da Pessoa Humana. Direito ao Esquecimento. Machismo Judicial. 


\section{ABSTRACT}

The object of this research reflects on the implementation of the right to be forgotten and judicial "machismo". The aim is to investigate the recognition of the right to be forgotten as a tutelage tool to the dignity of the human person and the biased gender inequality perpetrated by the Supreme Court during the trial of the cases under discussion. For this, we used the deductive method, with allowance for bibliographic and documentary research and the succession of three stages. At first, we sought to examine the judicial discourse with the observance of some cases tried by the Supreme Court, establishing some foundations that support the right to be forgotten. In the second, we studied the principle of human dignity and the grounds for the recognition of the right to forgotten under the focus of the Brazilian regulatory framework and transnational and doctrinal. The third and final step, we investigated the STJ was biased gender inequality in that it is the recognition of the right to forget some cases prosecuted. The main conclusion to be reached is that it is proper legal grounds for the right to be forgotten, as this right stems from the dignity of the human person and is categorized as good of personality, on the other hand, if the court points machismo STJ in order to recognize the right to be forgotten to male authors and the authors reject it female.

\section{KEYWORDS}

Human Dignity. Right to Forgotten. Judicial “Machismo”.

\section{RESUMEN}

El objeto de esta investigación, refleja sobre la aplicación del derecho al olvido y el machismo judicial. El objetivo es investigar el reconocimiento del derecho al olvido como una herramienta tutelar a la dignidad de la persona humana y la desigualdad de género perpetrado por la Corte Suprema en el juicio de los casos en discusión. Para ello, se utilizó el método deductivo, con una previsión de la investigación bibliográfica y documental y la sucesión de tres etapas. En un primer momento, hemos tratado de examinar el discurso judicial con la observancia de algunos casos juzgados por el Tribunal Supremo, el establecimiento de algunas fundaciones que apoyan el derecho a ser olvidado. En el segundo, se estudió el principio de la dignidad humana y los motivos para el reconocimiento del derecho al olvido bajo el enfoque del marco regulatorio brasileño y transnacional y doctrinal. El tercer y último paso, que investigó el STJ fue parcial desigualdad de género en que se trata del reconocimiento del derecho a olvidar algunos casos procesados. La principal conclusión que se puede llegar es que es fundamento legal adecuado para el derecho al olvido, ya que este derecho se deriva de la dignidad de la persona humana y se clasifica como bien de la personalidad, por el contrario, si los puntos de corte machismo STJ para reconocer el derecho al olvido a autores masculinos y los autores rechazan femenina.

\section{PALABRAS CLAVE}

Dignidad Humana. Derecho a ser olvidado. Machismo Judicial. 


\section{INTRODUÇÃO}

É indiscutível admitir que a transformação da sociedade agrária do século XIX para a sociedade urbana e industrial do século XX e a transição para a sociedade informatizada do século XXI, somada à maior participação de indivíduos no exercício do direito de sufrágio, potencializou e corroborou para a consciência dos direitos da personalidade. Com a modificação da sociedade e a substituição gradativa de seus valores, de seus costumes mais simples por relações mais complexas, do surgimento do consumo de massa e do avanço tecnológico, sobretudo com o surgimento da internet, inclusive com o avanço das redes sociais na web, o conteúdo dos direitos da personalidade foi se emergindo.

Se de um lado, o acesso ao fluxo informacional facilita a interação na vida das pessoas, por outro, traz consigo os perigos do "superinformacionismo" e da exposição desmesurada. E este aspecto negativo pode causar vulnerações capazes de atingir frontalmente algum dos bens da personalidade. E é aqui que se inclui o debate sobre o que vem sendo denominado "direito ao esquecimento".

Não raro, a inserção de informação na rede mundial de computadores tem afastado a possibilidade das pessoas, gradualmente, abandonar e esquecer o passado, pois nem sempre é possível "deletá-la", visto que, uma vez incorporadas no espaço digital, as informações ali armazenadas podem ser levadas para a eternidade.

Com relação ao reconhecimento do direito ao esquecimento, tudo caminha para que o mesmo encontre abrigo no cenário jurídico mundial. No Brasil, o enunciado 531 do Conselho da Justiça Federal reconhece o direito ao esquecimento.

Por outro lado, tem se observado, nas poucas decisões enfrentadas pelo STJ, um tendencioso machismo em reconhecer o direito ao esquecimento quando o mesmo é reclamado por mulheres, a exemplo do caso Aída Curi e caso Xuxa Vs. Google.

Ora, conforme se observará, o magistrado não é capaz de decidir sem a sua subjetividade, sendo assim, não consegue decidir sem isenção de suas emoções, distanciando de sua vivência e experiência. O juiz não é somente juiz, é também solteiro ou casado, é inquilino ou proprietário, é agricultor ou professor, é religioso ou ateu, é negro ou branco, é homem ou mulher, logo, é razoável afirmar que as suas condições pessoais repercutem em suas decisões, e é nesse exato momento em que o machismo judicial pode aflorar.

Portanto, para o desenvolvimento da pesquisa, procedeu-se a um recorte para analisar somente as decisões cotejadas pelo STJ. Para tanto, utilizou-se o método dedutivo, com subsídio em pesquisa bibliográfica e documental e a sucessão de três etapas. Na primeira, buscou-se examinar o discurso judicial com a observância de alguns casos julgados pelo STJ, estabelecendo-se os fundamentos que sustentam o direito ao esquecimento. Na segunda, estudou-se o princípio da dignidade da pessoa humana e os fundamentos para o reconhecimento do direito ao esquecimento sob o enfoque do marco normativo brasileiro e transnacional e doutrinário.

E, na terceira e última etapa, verificou-se como o STJ foi tendencioso à desigualdade de gênero no que pertine ao reconhecimento do direito ao esquecimento diante da obervância de alguns casos julgados. A principal conclusão que se chegou é que é adequada a fundamentação jurídica do direito ao esquecimento, pois tal direito decorre da dignidade da pessoa humana e é categorizado como bem da personalidade, por outro lado, se aponta o machismo judicial do STJ de forma a reconhecer o direito ao esquecimento quando envolvido interesse de pessoas do sexo masculino e rejeitá-lo em sentido contrário (sexo feminino). 


\section{CASOS CONCRETOS ENVOLVENDO O DIREITO AO ESQUECIMENTO APRECIADOS PELO STJ CDISCUR- SO JUDICIAL]}

No Brasil, sobre a evocação do direito ao esquecimento, merecem ser destacados dois julgados enfrentados pelo STJ. Trata-se do caso da Chacina da Candelária (Resp. 1.334.097) e o caso Aída Curi (Resp 1.335.153), ambos julgados no dia 28/5/2013.

No primeiro caso, a $4^{\mathrm{a}}$ turma do STJ reconheceu o direito ao esquecimento de um homem que foi julgado inocente pela acusação de participação no caso que ficou conhecido como a Chacina da Candelária. Neste caso, oito jovens, sendo seis menores foram assassinados por policiais militares enquanto dormiam próximo a Igreja da Candelária, localizada na cidade do Rio de Janeiro.

Ocorre que, anos depois de ser absolvido, o programa de televisão conhecido como Linha Direta, da TV Globo, retratou a história de forma a apontar o homem inocentado como coautor da Chacina da Candelária. 0 homem argumentou, por meio da ação de indenização proposta na Justiça, que negou pedido de entrevista feito pelo programa Linha Direta, mesmo assim, este foi veiculado em rede nacional de televisão, citando-o como um dos envolvidos na chacina.

O interessado argumentou que já havia superado o trauma da acusação, entretanto, a transmissão do programa promoveu na sociedade em que vivia o escárnio popular e a imagem de chacinador, ferindo o seu direito de ser deixado em paz e a sua privacidade.

Ao julgar o caso, a $4^{\mathrm{a}}$ Turma manteve a sentença de primeiro grau e condenou a emissora ao pagamento de indenização no valor de R\$ 50.000,00 (cinquenta mil reais), sob o argumento de que o réu, condenado ou absolvido pela prática de um crime, tem o direito de ser esquecido, alegando que até mesmo os conde- nados que já cumpriram a pena têm direito ao sigilo da folha de antecedentes e a exclusão dos registros de condenação.

Entendeu o órgão julgador que, por maiores e melhores razões aqueles que foram absolvidos não podem continuar com este estigma, conferindo-lhes o mesmo direito de ser esquecidos. Por outro lado, sustentou que a ocultação do nome e da fisionomia do autor da ação não macularia sua honra nem a liberdade de imprensa.

O segundo caso trata-se da história de Aída Curi que também foi apresentado pelo Programa Linha Direta da Rede Globo de Televisão. 0 programa trouxe à baila o crime contra Aída Curi ocorrido em 1.958. Após ser abusada sexualmente por três homens, a vítima, com apenas 18 anos de idade, foi atirada do alto de um edifício, localizado na Avenida Atlântica, bairro de Copacabana no Rio de Janeiro. Ela faleceu em decorrência da queda.

A emissora retratou o crime com a divulgação do nome da vítima e de fotos reais da mesma. Os irmãos da vítima entraram com uma ação contra a emissora com o objetivo de receber indenização por danos morais, materiais e à imagem. Fundamentaram o seu pedido sob o argumento de que, ao ser retratado o crime, este trouxe a lembrança deste e todo o sofrimento causado por ele.

Por maioria dos votos, a mesma $4^{\mathrm{a}}$ Turma do STJ entendeu que, neste caso, o crime era indissociável do nome da vítima, e que, mesmo sem consentimento da família, não configurou abalo moral indenizável a exibição da história do crime por meio de dramatizações. Entendeu ainda a $4^{\mathrm{a}}$ turma que não era possível que a emissora retratasse esta história omitindo o nome da vítima e que o foco da reportagem foi no crime e não na vítima.

Assim, nota-se que no primeiro caso, a $4^{\mathrm{a}}$ turma do STJ reconheceu o direito ao esquecimento para um 
homem inocentado da acusação de envolvimento na Chacina da Candelária, por outro lado, esta mesma turma negou tal direito aos familiares de Aída Curi sob o fundamento de que: "o acolhimento ao direito ao esquecimento, com a consequente indenização, consubstancia desproporcional corte à liberdade de imprensa, se comparado ao desconforto gerado pela lembrança".

Outro caso concreto bastante interessante é o que envolve uma ação judicial movida pela apresentadora de televisão Maria das Graças Xuxa Meneghel contra a empresa provedora de pesquisa Google, em decorrência de ter participado do filme Amor, estranho amor - 1982, em que a mesma aparece nua praticando ato sexual com um garoto de 12 anos. REsp 1.316.92 (caso Xuxa vs. Google Search).

Por ter se tornado uma famosa apresentadora de um programa infantil, a atriz em tela buscou remover dos sites de pesquisas os resultados relativos à busca pela informação "Xuxa pedófila” em que aparecem imagens vinculadas ao filme em tela. Sustentou a atriz a tese que remete ao direito ao esquecimento para não ter que pagar por uma pena perpétua pelo que já fez no passado. Requereu que tais informações fossem banidas da internet com forma de preservar a sua imagem e como forma de garantia de sua dignidade. De outro lado, a aludida provedora de pesquisa alegou que não poderia monitorar tudo o que os usuários escrevem.

Em julgado datado de 26 de junho de 2012, a $3^{a}$ Turma do STJ, por unanimidade decidiu que o Google era apenas um facilitador de informação e, por isso, a ação deveria ser movida contra aqueles que veicularam os dados, razão pela qual, julgou improcedente 0 pedido da autora.

Desse modo, percebe-se que a aplicação do direito ao esquecimento, embora sem parâmetros adequados, já é aplicado no Brasil, sobretudo por conta da sua importância na tutela dos direitos humanos que ancoram os direitos da personalidade invocados em todos os casos retro mencionados.

\section{BREVES NOTAS SOBRE A CONSTRUCĞ̃O DO DIREITO AO ESQUECIMENTO.}

É irrefutável afirmar que a tendência dos ordenamentos jurídicos é o reconhecimento do ser humano como centro e fim do direito. Esta propensão encontra-se pautada, entre outros motivos, na reação dos Estados democráticos após a traumática superação da ideologia nazifascista que desprezava a vida humana, característica predominante dos regimes totalitários. Com efeito, as mudanças políticas, econômicas e sociais produzidas pelas duas Guerras Mundiais refletiram de forma imediata nas Declarações de Direitos, principalmente na Declaração Universal de Direitos Humanos, de 10 de dezembro de 1.948 (DUDH-48).

A pessoa humana passou a merecer valorações cardinais para o Direito, outorgando-se elevada importância à personalidade, corroborando-se a ideia de que é a pessoa a figura mais relevante para a sociedade. Surgiu, com efeito, o fenômeno que a doutrina autorizada denomina de "repersonalização do Direito", que se traduziu na positivação na Constituição de uma matéria que era antes exclusiva dos fechados Códigos Civis, e a adoção pelos ordenamentos jurídicos de direitos humanos como diretrizes essenciais do Estado. Foram estes incorporados na Constituição como direitos e garantias fundamentais dedicados a proteger ao indivíduo.

À guisa de ilustração substantiva, a Constituição da República Italiana, de 27 de dezembro de 1947, adotou esta perspectiva no artigo $3^{\circ}$. 0 preceito, também, tem seu fundamento na citada DUDH-48, a qual estabeleceu os direitos humanos mínimos que um Estado deve respeitar para que seja qualificado de democrático, e que no preâmbulo declarou "Considerando que o reconhecimento da dignidade inerente a todos os membros da família humana e de seus direi- 
tos iguais e inalienáveis é o fundamento da liberdade, da justiça e da paz no mundo", completando o raciocínio no artigo $1^{02}$.

Na mesma linha, a Lei Fundamental de Bonn, de 23 de maio de 1949, tem acolhimento formal do valor dignidade da pessoa humana no artigo 1.1. Não destoante, a Constituição da República Portuguesa, de 25 de Abril de 1976, proclama a dignidade no seu art. $1^{\circ}$. Com a mesma inteligência, a Constituição Espanhola, de 29 de Dezembro de 1978, dispõe sobre a dignidade no art. 10.1.

No mesmo sentido, contemplando a dignidade da pessoa humana, pode-se citar a constituição da Itália, da Turquia, da Grécia e da Alemanha. No Leste Europeu, destaca-se a Constituição da Polônia, da Rússia e da Estônia. No continente Africano, ressalte-se a Constituição da África do Sul, da Etiópia e de Guiné. No Continente Americano, destaca-se a Constituição do Paraguai, de Cuba, do Peru, do Chile e da Guatemala (HÄBELE, 2007).

E, por fim, o constitucionalismo brasileiro, também, albergou a dignidade da pessoa humana como fundamento imperativo da República Federativa do Brasil no art. $1^{\circ}, \mathrm{II}^{3}$. É por isso que é coerente afirmar que "é no princípio da dignidade humana que a ordem jurídica encontra seu próprio sentido, sendo seu ponto de partida e seu ponto de chegada, para a hermenêutica constitucional contemporânea" (PIOVESAN, 2010, p. 7).

2. Insta registrar a que a Declaração Americana dos Direitos e Deveres do Homem (1948) no seu preâmbulo aduz "Todos os homens nascem livres e iguais em dignidade e direitos e, como são dotados pela natureza de razão e consciência, devem proceder fraternalmente uns para com os outros".

3. Ademais, urge indicar que o Pacto Internacional dos Direitos Civis e Políticos (PIDCP) de 1966 (Decreto n 592, de 6/7/1992), no seu preâmbulo disciplina que: "Considerando que, em conformidade com os princípios proclamados na Carta das Nações Unidas, o reconhecimento da dignidade inerente a todos os membros da família humana e dos seus direitos iguais e inalienáveis constitui o fundamento da liberdade, da justiça e da paz no mundo, Reconhecendo que esses direitos decorrem da dignidade inerente à pessoa humana [...]". Ainda, a Convenção Americana de Direitos Humanos de 1969 (Pacto de San José da Costa Rica) (Decreto $n^{\circ} 678$, de 6/11/1992) regula no seu artigo $5^{\circ}$ que: "Direito à integridade pessoal. §1. Toda pessoa tem direito a que se respeite sua integridade física, psíquica e moral. §2. Ninguém deve ser submetido a torturas, nem a penas ou tratos cruéis, desumanos ou degradantes. Toda pessoa privada de liberdade deve ser tratada com o respeito devido à dignidade inerente ao ser humano
Ao teor do que antecede é inegável admitir, pois, que as circunstâncias históricas, sociais e políticas levaram à proteção da personalidade do ser humano, e a consequente adoção pelos Estados de um valor básico enraizado e encontradiço em qualquer sociedade plural e democrática: a dignidade da pessoa humana como fundamento da Constituição. Neste contexto, é irretorquível interpretar que a alocação do princípio democrático na base do processo de formação da vontade do Estado legitimou a mencionada positivação da dignidade da pessoa humana (VESSONI, 2005).

Com efeito, é afluente perceber que da dignidade da pessoa humana reside na potencialidade de que cada indivíduo, dotado de igual consideração e respeito por parte da comunidade em que se insere, formule e ponha em prática seu plano ideal de vida, traçando os rumos que entende mais afeitos ao livre desenvolvimento de sua personalidade (SARMENTO, 2004).

Neste contexto, algumas destas possibilidades, as mais elevadas e das quais não se pode prescindir, são representadas, segundo Luís Roberto Barroso (2013) nos direitos humanos (ou fundamentais). Barroso (2013, p. 75) observa que a dignidade da pessoa humana e os direitos humanos têm interna relação como se fossem duas faces de uma mesma moeda: uma de corte filosófico, que "expressa os valores morais que singularizam todas as pessoas, tornando-as merecedoras de igual respeito e consideração", a outra de corte jurídico, contemplando os direitos humanos (fundamentais), que "representam a moral sob a forma de Direito".

Neste tom, o "reconhecimento da centralidade dos direitos humanos corresponde a um novo ethos de nossos tempos" (CANÇADO TRINDADE, 2006, p. 112). Importa refletir, nada obstante, como faz Joaquín Herrera Flores (2009), que toda sociedade tem cultura própria, que o mundo é o que está no meio entre o excesso e a falta de sentido, que toda sociedade tem sua forma particular de buscar a dignidade, que em toda sociedade há quem aceite a hegemonia e há 
quem lute contra, que a luta antagonista pela dignidade tem plurais vias de alcance, e que o universal não são os direitos humanos, é a ideia ou intuição de dignidade humana.

Eis a necessidade de se pensar num direito ao esquecimento como forma de tutelar a dignidade humana: é preciso lembrar que é preciso esquecer para se ter uma vida digna! E o direito não está alheio a esta realidade, ele não só acompanha as transformações sociais, como também as inaugura.

Pode-se afirmar que, no Brasil, o direito ao esquecimento possui assento constitucional e legal, considerando que é uma consequência do direito à dignidade da pessoa humana e aos direitos da personalidade, como a vida privada, a intimidade e a honra assegurados pela Constituição Federal de 1.988 em seu artigo 1º III e art. $5^{\circ}$, X, e pelo Código Civil de 2002, em seu artigo 11.

Assim é que o princípio da dignidade da pessoa humana deve ser reconhecido a todos os cidadãos. Sendo este princípio uma cláusula geral de tutela aos direitos da personalidade que deve ser aplicada para a proteção da privacidade, intimidade, honra entre outros (SZANIAWSKI, 2005).

De um lado, defende-se que haveria "uma lista de direitos autônomos entre si” (teoria pluralista) e, de outro, "um direito geral que tem como conteúdo a pessoa humana em seus vários aspectos, mas reunidos numa unidade" - teoria monista. (BORGES, 2005, p. 25).

Contudo, refuta-se esta última (teoria monista) pelo óbvio, uma vez que os direitos a personalidade são diversos e não um único direito, tendo em vista que os bens tutelados são díspares na comparação de um com outro, da mesma forma como se desassemelham as características de cada um deles pela sua singularidade (BITTAR, 2000).

Nesse sentido, Roxana Cardoso Brasileiro Borges (2005, p. 43) ensina que os direitos da personalidade não são numerus clausus, o catálogo está em contínua expansão pois "a evolução do sistema objetivo (direito positivo) e do sistema científico (evolução doutrinária) leva ao reconhecimento, a cada dia, de novos direitos da personalidade".

Foi nesse sentido o entendimento de alguns renomados juristas brasileiros ao se reunir em março de 2013, perante o Conselho da Justiça Federal (CJF), ao editar o enunciado $\mathrm{n}^{0} 531$ da VI Jornada de Direito Civil do Conselho da Justiça Federal - CJF, que reconheceu a possibilidade de tutela do direito ao esquecimento ao dispor que "a tutela da dignidade da pessoa humana na sociedade da informação inclui o direito ao esquecimento".

Fora do Brasil, o Estado da Califórnia recentemente criou a Lei SB 568, apelidada de "Lei Delete" (ou "Eraser Button Law") a qual permitirá apagar o passado digital de condutas praticadas por crianças e adolescentes. Também, a Europa já estuda uma forma de regulamentação em que o usuário passará a ter um maior controle em relação aos seus dados que circulam na internet. Trata-se da proposta de Regulamento COM/2012/011.

Nesse sentido, aduz Vance Packard (apud DONEDA, 2006, p. 178), que: "com episódios de nosso passado sendo cada vez mais armazenados em arquivos e computadores, a possibilidade de recomeçar de novo está se tornando mais difícil”. E arremata: “A noção cristã de redenção é incompreensível para o computador".

\section{REDUTO DA DESIGUALDADE DE GÊNERO}

Para dar início à pesquisa sobre o reduto de desigualdade entre homens e mulheres tem-se que, na antiguidade, a mulher foi educada para cuidar da casa, ou seja, cuidar dos outros, especialmente da família. As mulheres que trabalhavam fora de casa eram encaradas como desonestas. 0 trabalho remunerado 
era impróprio ao sexo feminino. A mulher era escravizada pelo marido e era considerada como um ser marginalizado, a quem se devia deixar no desconhecimento e na servidão.

O sexo só se justificava plenamente quando voltado para fins exclusivamente reprodutivos. As mulheres iniciaram seus trabalhos em atividades de baixo prestigio e com menor remuneração, apesar de sempre contribuir na economia familiar, o que fez com que a mesma assumisse diferentes papeis dentro e fora de casa.

No Código de Manu observa-se que em Roma a mulher era simplesmente tida como menor sujeita ao pai e ao marido. Por outro lado, os códigos nacionais negaram direitos à mulher casada, como o de gerir sua propriedade.

Criou-se uma evidência quanto à incapacidade feminina e natural superioridade masculina. A educação para a mulher não era muito valorizada no século XIX. Os homens operários não viam as mulheres como suas aliadas na luta pelos direitos trabalhistas; as mulheres ganhavam bem menos do que os homens para fazer a mesma atividade e, o direito de votar e ser votada foi e tem sido conquistado a duras penas.

O modelo patriarcal de família ainda hoje se vê em evidência quando se observa a autoridade masculina sobre a mulher. Isto ocorre porque, ainda hoje, o homem se sente o dono do corpo da mulher, fato que o presume autorizado a promover a violência física e psicológica contra ela.

Salienta Pinsky (2014, p. 304) que "de simples 'costela de adão’ à conquista da cidadania plena, é uma longa trajetória ainda não completada pelas mulheres". Adverte $o$ autor que as mulheres ainda sofrem com a "violência, salários menores e preconceitos de diferentes tipos". É com este estigma de subjugo que a mulher tem sido alvo das decisões judiciais quando a procura como último recurso para fazer valer os seus direitos.
Segundo os números preliminares do Censo dos Magistrados, realizado pelo Conselho Nacional de Justiça (CNJ) no final do ano passado (2013) divulgado no Plenário do CNJ, durante a $191^{\text {a }}$ Sessão Ordinária do Conselho, sobre o perfil da magistratura brasileira, tem-se que a maioria dos juízes é formada por homem branco, de 45 anos, casado e com filhos. É composta majoritariamente por homens. A pesquisa apontou que $64,1 \%$ dos magistrados do Brasil são do sexo masculino e $35,9 \%$ são do sexo feminino. Os juízes chegam a representar $82 \%$ dos ministros dos tribunais superiores.

Por outro lado, conforme já antecipado, o magistrado não é capaz de decidir sem a sua subjetividade, suas emoções, credos, logo, não nos parece razoável afirmar que as suas condições pessoais não irão repercutir em suas decisões.

Nesse sentido, Ferrajoli (2006) expôs em sua obra que existem limites que levam à incerteza da verdade processual. Um deles é o condicionamento do juiz ao seu ambiente social, pois sendo o magistrado tão vulnerável quanto qualquer outra pessoa, seria impossível se pensar numa dissociação absoluta entre a objetividade processual e a subjetividade individual.

Giacomolli e Duarte bem sintetizam o tema (2006, p. 288) ao afirmarem que: o juiz poderá até julgar de uma maneira formalmente imparcial (não ser parte), mas isso de longe suprime sua neutralidade subjetiva no processo, aquela projetada sobre o processo que diz das vivências pessoais do juiz, seus gostos e desgostos, suas paixões, seu eu, seu modo de ser no mundo, pois o sentido da compreensão não acontece sem a sobreposição sobre o objeto a ser analisado, sem a vivência do ser com seu entendimento singular, pousado sobre a realidade.

Ora, sendo a maioria dos ministros do STJ formados por homens, os quais foram educados, ainda, debaixo do ranso do subjugo à mulher, percebe-se que, não raro, aflora entre eles o machis- 
mo judicial, pois, acredita-se que foi este estigma de depreciação à mulher que se analisou nas duas decisões emandas no primeiro tópico desta pesquisa. Vejamos:

Ora, por ocasião do julgamento do REsp $n^{\circ}$ 1.335.153 (caso Aída Curi), entenderam os julgadores que, com o passar do tempo é possível de adquirir o direito ao esquecimento, considerando que, "na contramão, a dor vai diminuindo, de modo que, relembrar o fato trágico da vida, a depender do tempo transcorrido, embora possa gerar desconforto, não causa o mesmo abalo de antes". Sustentou o STJ que as instâncias ordinárias reconheceram que a imagem da falecida não foi utilizada de forma degradante ou desrespeitosa.

O julgado obteve um voto divergente, o qual sustentou que, o fato de o crime haver suscitado forte interesse coletivo à época em que ocorreu não é suficiente para mitigar o direito da vítima e de seus familiares de não ter a imagem da vítima divulgada, considerando a proteção legal à intimidade e à privacidade do morto e o sentimento comum de que as famílias não desejam ver seus mortos expostos em mídia televisiva.

Já no REsp 1.316.92 (caso Xuxa Vs. Google), o julgador entendeu que a vítima deveria acionar diretamente o autor do ato ilícito, sendo "incabível impor aos provedores de pesquisa a obrigação de eliminar do seu sistema os resultados que apontem para uma foto ou um texto específico".

Contudo, ao apreciar o REsp 1.334.097 (caso Chacina da Candelária), entendeu os ministros do STJ que, as notícias sobre a participação do autor, diga-se de passagem - homen, é apta a reacender a desconfiança geral acerca da índole do autor. Acrescetaram que "a indicação do nome e da imagem do autor resultaria em uma segunda ofensa à sua dignidade, só porque a primeira já ocorrerá no passado".
Assim, diante dos apontamentos efetuados, percebe-se o julgamento tendencioso do STJ quando deixa brotar o machismo judicial ao reconhecer o direito ao esquecimento ao homem envolvido no caso da chacina da Candelária e negar, sob argumentos diversos os pedidos vinculados às interessadas Aída Curi e à apresentadora de TV Maria das Graças Xuxa Meneghel.

Percebe-se nas entrelinhas que o discurso formulado pelos ministros não é contra o direito ao esquecimento, mas contra o tipo de exposição realizado. Trata-se, na verdade, de decisões voltadas para um discurso moralista e de fundo machista e que não contempla o princípio da igualdade entre os gêneros.

\section{CONCLUSÃO}

Não teve este texto a pretensão de esgotar o tema. Apenas sustenta-se que a doutrina, a jurisprudência e a comunidade científica brasileira devem estar preparadas para avançar na problematização decorrente da desigualdade de gênero, principalmente diante do reconhecimento de novos direitos, como é o caso do direito ao esquecimento. Na investigação sobre o objeto deste texto, apontam-se como resultados:

(i) É adequada a fundamentação jurídica do direito ao esquecimento, pois tal direito decorre da dignidade da pessoa humana e é categorizado como bem da personalidade, pois incluído na releitura da privacidade.

(ii) A desigualdade de gênero ocorre desde os tempos primórdios e esta é a razão de pano de fundo para explicar o machismo judicial, uma vez que o julgador apresenta os aspectos subjetivos na decisão, e, não foi diferente com os ministros do STJ ao julgar dois dos casos cujas vítimas eram do sexo feminino abordados nesta pesquisa.

(iii) Há que se reconhecer que houve avanços no reconhecimento dos direitos das mulheres, contudo, como também há preocupação pela efetividade dos 
direitos alcançados, a exemplo dos questionamentos quanto à constitucionalidade da Lei Maria da Penha.

0 direito ao esquecimento é um tema novo que carece da sensibilidade do aplicador do direito para ser reconhecido ante a sua ausência de regulamentação. Esta sensibilidade dificulta a aplicação de tal direito quando são as mulheres as requerentes, isto porque, conforme visto, a maioria dos julgadores são homens.

Assim, diante do exposto, à luz da teoria crítica dos direitos humanos, percebe-se que um grande desafio para o aplicador do direito é realizar uma troca de lentes para se despir de qualquer preconceito de raça, credo, gênero etc., como forma de proteção à dignidade da pessoa humana e proporcionar uma sociedade, livre, justa, igualitária e solidária.

\section{REFERÊNCIAS}

BARROSO, Luís Roberto. A dignidade da pessoa humana no direito constitucional contemporâneo. A construção de um conceito jurídico à luz da Jurisprudência mundial. Belo Horizonte: Fórum, 2013.

BITTAR. Carlos Alberto Bittar \& BITTAR FILHO, Carlos Alberto. Os direitos da personalidade. Rio de Janeiro: Forense, 2010.

BORGES, Roxana Cardoso Brasileiro. Disponibilidade dos direitos de personalidade e autonomia privada. São Paulo: Saraiva, 2005.

COMISSÃO EUROPEIA - Diretiva COM/2012/010 E COM/2012/011, Bruxelas 2012. Disponível em: <http://eur-ex.europa.eu/LexUriServ/LexUriServ. do?uri=COM:2012:0010:FIN:PT:PDF>. Acesso em: 30 out. 2013.

DONEDA, Danilo. Da privacidade à proteção dos dados pessoais. Rio de Janeiro: Renovar, 2006.
FERRAJOLI, Luigi. Direito e razão. Trad. Ana Paula Zomer Sica, Luiz Flávio Gomes, Juarez Estevam Xavier Tavaras e Fauzi Hassan Choukr. São Paulo: RT, 2006.

GIACOMOLLI, Nereu José; DUARTE, Liza Bastos. O mito da neutralidade na motivação das decisões judiciais: aspectos epistemológicos. Revista da Ajuris, Porto Alegre: Ajuris, n.102, 2006. Disponível em: <http://livepublish.iob.com.br/ntzajuris/lpext.dll/ Infobase/1722f?f=templates\&fn=document-frame. htm\&2.0>. Acesso em: 30 out. 2013.

HÄBERLE, Peter. A dignidade humana e a democracia pluralista: seu nexo interno. In: SARLET, I. W. (Org.). Direitos fundamentais, informática e comunicação: algunas aproximações. Porto Alegre: Livraria do Advogado, 2007, p.11-28.

HERRERA FLORES, Joaquín. Teoria Crítica dos Direitos Humanos. Os direitos humanos como produtos culturais. Rio de Janeiro: Lumen Juris, 2009.

JUSTIÇA FEDERAL. Enunciados aprovados na VI Jornada de Direito Civil. Disponível em: <http://www.jf. jus.br/cjf/CEJ-Coedi/jornadas-cej/VI\%20JORNADA1. pdf>. Acesso em: 20 out. 2013

PINSKY Carla Bassanezi; PEDRO, Joana Maria. Igualdade e Especificidades. In: PINSKY, Jaime; PINSKY, Carla Bessanezi (Orgs.). História da Cidadania. 6.ed. São Paulo: Contexto, 2014.

PIOVESAN, Flávia. A Incorporação, a Hierarquia e o Impacto dos Tratados Internacionais de Proteção dos Direitos Humanos no Direito Brasileiro. In: GOMES, Luiz Flávio; PIOVESAN, Flávia (Coords.). 0 Sistema de proteção dos direitos humanos e o direito brasileiro. São Paulo: Revista dos Tribunais, 2000.

SARLET, Ingo Wolfgang. A eficácia dos direitos fundamentais. 2.ed. Porto Alegre: Livraria do Advogado, 2007. 
SARMENTO, Daniel. Direitos fundamentais e relações privadas. 2.ed. Rio de Janeiro: Lumen Juris, 2004.

SZANIAWSKI, Elimar. Da tutela dos direitos de personalidade no Brasil. In: SZANIAWSKI, Elimar. Direitos de personalidade e sua tutela. 2.ed. rev., atual. e ampl. São Paulo: Revista dos Tribunais, 2005.
TRINDADE, Antônio Augusto Cançado. A humanização do direito internacional. São Paulo: Del Rey, 2006.

VESSONI, Elaine Parpinelli Moreno. A força normativa da Constituição, Konrad Hesse e a Essência da Constituição, Ferdinand Lassale (comentários bibliográficos). Revista Brasileira de Direito Constitucional, n.5, jan./jun., 2005. 